Burnley match on BT Sport on 26th February where both football clubs had shirt sponsorship by gambling brands. FUN88, Newcastle's principal sponsor and a China-based online gaming firm, received 109 exposures at this single match whilst bet365, another sponsor, received 190. Whilst gambling companies were the most referenced (921) across the five matches analysed, there were also a combined 217 references to alcohol and food and beverages. Across all five games, there was a mean of 1.3 exposures to unhealthy products each minute $(2.1$ during Newcastle United $\mathrm{v}$ Burnley).

Conclusion Results show that watching men's football on television exposes the global audience, including many young people, to a significant level of advertising of unhealthy commodities. Given contemporary challenges to public health, such as obesity and non- communicable diseases (including mental health), and that marketing is intended to influence purchasing behaviour, the UK government, the EPL and its membership clubs should consider regulating EPL clubs' commercial relationships where these have the potential to damage fans' and viewers' health.

\section{OP06 QUANTIFYING THE POTENTIAL HEALTH IMPACT OF RESTRICTING LESS-HEALTHY FOOD ADVERTISING ON UK TELEVISION BETWEEN 0530 AND 2100: A MULTI- STATE LIFETABLE MODELLING STUDY}

${ }^{1} \mathrm{OT}$ Mytton* ${ }^{*}{ }^{2} \mathrm{E}$ Boyland, ${ }^{1} \mathrm{~J}$ Adams, ${ }^{3} \mathrm{~B}$ Collins, ${ }^{4} \mathrm{M}$ O'Connell, ${ }^{5} \mathrm{~S}$ Russell, ${ }^{4} \mathrm{~K}$ Smith, ${ }^{4} \mathrm{R}$ Stroud, ${ }^{5} \mathrm{R}$ Viner, ${ }^{6} \mathrm{~L}$ Cobiac. 'MRC Epdiemiology Unit, University of Cambridge, Cambridge, UK; ${ }^{2}$ Department of Psychological Sciences, University of Liverpool, Liverpool, UK; ${ }^{3}$ Department of Public Health and Policy, University of Liverpool, Liverpool, UK; ${ }^{4}$ Institute for Fiscal Studies, London, UK; ${ }^{5}$ Great Ormond Street Institute of Child Health, University College London, London, UK; ${ }^{6}$ Nuffield Department of Population Health, University of Oxford, Oxford, UK

\subsection{6/jech-2020-SSMabstracts.6}

Background To tackle childhood obesity, the UK Government is consulting on prohibiting the advertising of high fat sugar salt foods (HFSS) on television between 0530 and 2100. We sought to estimate the health impact of this policy in the UK. Methods Informed by a literature review, we adapted an existing multi-state lifetable model (PRIMETime) to model the impact of television advertising exposure on children's caloric intake, and the subsequent impact on body mass index and health.

We used data from AC Nielsen and Broadcasters' Audience Research Board data (2015) on children's exposure to HFSS advertising (adopting the FSA-Ofcom definition of HFSS); published meta-analysis quantifying the effect of less-healthy food advertising on caloric intake in children; the Human Mortality Database for the UK (2015) on population numbers and all-cause mortality rates; the Health Survey for England (2016) on body mass index; the Global Burden of Disease Study for disability weights to estimate Disability Adjusted Life Years (DALYs).

We simulated a closed cohort of the UK population aged 0-17 years in $2015(n=13,729,000)$, following the cohort to death. We assumed HFSS advertising had no effect on adults, and that changes in mean BMI observed at age 17 years persisted throughout adult life.

The main outcome measures were change in percentage of the children (aged 5-17 years) with obesity defined using International Obesity Task Force cut-points, and change in health status (DALYs). Monte Carlo analysis was used to estimate 95\% uncertainty intervals.

We compared three scenarios:

A. All HFSS advertising between 0530 and 2100 is withdrawn

B. All HFSS advertising between 0530 and 2100 is displaced to 2100 to 0530

C. No intervention

Results If all HFSS advertising between 0530 and 2100 was withdrawn, we estimate that UK children would decrease caloric intake by $9.1 \mathrm{kcal}$ (95 CI: $0.5 \mathrm{kcal}-17.7 \mathrm{kcal}$ ), which would reduce the number of children with obesity by 40,000 $(12,000-81,000)$ or $4.6 \%(1.4 \%-9.5 \%)$ compared to no intervention. This would avert 240,000 (65,000-530,000) DALYs across the cohort's lifetime. Under a scenario where all HFSS advertising is displaced to 2100 to 0530 , we estimate that the benefits would be reduced by around two-thirds.

Conclusion Measures that reduce exposure to less-healthy food advertising on television, such as restricting HFSS advertising between 0530 and 2100, could make a meaningful contribution to reducing childhood obesity. The impact of this policy may be reduced if adverts are displaced to after 2100 rather than being withdrawn.

\section{OP07 FACTORS INFLUENCING WOMEN'S FOOD CHOICES AND SUPPORT THEY REQUIRE TO MAKE HEALTHIER FOOD CHOICES IN SUPERMARKETS - A QUALITATIVE STUDY}

${ }^{1} \mathrm{P}$ Dhuria*, ${ }^{1,2} \mathrm{~W}$ Lawrence, ${ }^{1} \mathrm{~S}$ Crozier, ${ }^{1,2} \mathrm{C}$ Cooper, ${ }^{1,2} \mathrm{~J}$ Baird, ${ }^{1,2} \mathrm{C}$ Vogel. ${ }^{1}$ Medical Research Council Lifecourse Epidemiology Unit, University of Southampton, Southampton, UK; ${ }^{2}$ National Institute for Health Research Biomedical Research Centre, University of Southampton, Southampton, UK

\subsection{6/jech-2020-SSMabstracts. 7}

Background Supermarkets are a major source of food for families and women remain primarily responsible for food shopping tasks. The factors women perceive to influence their food shopping choices are poorly understood, particularly in relation to in-store layout. We aimed to examine women's perceptions of factors that influence their food shopping choices, including product placement in-store, and identify ways that supermarkets could support healthier food shopping choices.

Methods In this qualitative cross-sectional study, semi-structured telephone interviews were conducted with a random sample of 20 women customers aged 18-45 years. Women were recruited from six supermarkets across England. Participants were asked to describe the reasons for their choice of supermarket and factors in-store that prompted their food selections. The actions supermarkets', governments' and customers' can take to encourage healthier food shopping choices were explored. Thematic analysis was conducted using QSR NVIVO software 11 to identify key themes. Four researchers were involved in developing the initial coding framework, double coding of six interview transcripts and refining the coding framework.

Results Participants had a median age of 39.5 years (IQR: $35.1,42.3$ ), median weekly grocery spend of $£ 70$ (IQR: 50, 88 ), and $44 \%$ had left school aged 16 years. Six key themes were identified: 1) Physical Environment, 2) Value for Money, 3) Influence of Family, 4) Physiological/Psychological State, 5) Healthy Eating Priorities and 6) Level of Awareness of Food Decisions. Women reported that achieving value for money, 
feeling hungry, tired, or stressed, and meeting family members' food preferences influenced their food shopping choices. The physical environment was also important, including product quality and variety, plus ease of accessing the store or products in-store. Some participants described taking a highly conscious approach to making food choices while shopping (i.e. lists), but many described how they and their family made unintended food selections as a result of prominent placement of unhealthy products. In addition to these six themes, participants described healthy eating as a personal responsibility but some stated that governments and supermarkets could be more supportive to help customers make healthier food shopping choices.

Conclusion This study identified a number of factors that influence women's food shopping choices and described how current placement strategies can shape these, particularly in a less aware manner. Creating healthier supermarket environments could produce a shared responsibility for healthy eating. Future research could further explore perceptions that healthy eating is a personal rather than a societal or business responsibility.

\section{OP08 UNDERSTANDING PRACTICES AND CHALLENGES OF (RE-)LOCALISING FOOD PRODUCTION AND CONSUMPTION IN SMALL ISLAND DEVELOPING STATES FOR BETTER NUTRITION: A QUALITATIVE MULTI-SITE STUDY}

${ }^{1} \mathrm{C}$ Guell ${ }^{*},{ }^{2} \mathrm{C}$ Brown, ${ }^{3} \mathrm{~V}$ lese, ${ }^{3} \mathrm{O}$ Navunicagi, ${ }^{3} \mathrm{M}$ Wairiu, ${ }^{1,4} \mathrm{~N}$ Unwin. ${ }^{1}$ European Centre for Environment and Human Health, University of Exeter Medical School, Truro, UK; ${ }^{2}$ George Alleyne Chronic Disease Research Centre, University of the West Indies, Bridgetown, Barbados; ${ }^{3}$ Pacific Centre for Environment and Sustainable Development, University of the South Pacific, Suva, Fiji; ${ }^{4}$ MRC Epidemiology Unit, University of Cambridge, Cambridge, UK

10.1136/jech-2020-SSMabstracts.8

Background Populations in Small Island Developing States have a high burden of malnutrition, including some of the highest rates globally of obesity and related non-communicable diseases. Underlying this burden is a growing reliance on low nutritional quality food imports, and improving food sovereignty and health through the production and consumption of local nutritious foods is therefore an urgent goal by national governments and regional organisations. As part of a larger project to develop evaluative methods, we aimed to explore factors affecting local food production and consumption, and communities' perceived impacts of local foods on health and socio-economic wellbeing in Fiji in the South Pacific and Saint Vincent and the Grenadines in the Caribbean.

Methods In the two settings, we conducted in total 52 indepth, semi-structured one-on-one interviews with key stakeholders involved in local food production, processing, trade and policy, as well as 28 focus groups with rural and urban, tenant and landowning communities of adult and young adult ages. Country teams and co-investigators jointly thematically analysed the transcripts using the software Dedoose. We placed emphasis on understanding commonalities and differences within and across contexts.

Results Across both settings in the Pacific and Caribbean, common concerns largely outweighed differences. Participants noted that while local food production was seen as essential to local nutrition policies for population health, government support was perceived to be limited, outdated (e.g. not recognising traditional agricultural methods) and funding declining rather than decreasing over the past decades. Local food producers saw themselves as marginalised against a backdrop of increasing preference for imported foods, yet also experienced an increasing interest and pride in local produce which potentially provides increased commercial opportunities. Narratives in the community focus groups contained corresponding tensions, highlighting the health and economic value of homeproduced foods, yet observing increasing social and generational changes towards buying and consuming processed foods. Many participants in both settings suggested that greater resilience could be achieved through cooperation and self-reliance on home food production but experienced many challenges related to environmental change such as extreme weather, pollution by pesticides and plastics, and to social conflicts and pressures such as limited access to land for home growing.

Conclusion Local community food production initiatives in Small Island Development States can be supported by understanding and addressing these complex challenges faced along the food value chain as well as by understanding local food practices, values and systems and their place in global networks.

On behalf of the CFaH Team

Funding Funded by the Global Challenges Research Fund through the UK Medical Research Council; Grant No. MR/ P025250/1.

\section{Wednesday 9 September}

\section{Session: Mental Health: Record Linkage}

\section{OP09 UNDERSTANDING THE MENTAL HEALTH OF CHILDREN KNOWN TO SOCIAL SERVICES IN NORTHERN IRELAND: AN ADMINISTRATIVE DATA LINKAGE STUDY}

S McKenna*, A Maguire, D O'Reilly. Centre for Public Health, Queen's University, Belfast, UK

\subsection{6/jech-2020-SSMabstracts.9}

Background Research suggests that children known to social services experience a higher prevalence of mental ill-health compared to their peers. However, previous studies have been limited based on sample sizes, comparison populations and level of detail around care interventions. Northern Ireland (NI) is unique as it has an integrated health and social care system holding data centrally on all individuals known to social services, allowing for a population wide examination of the mental health of children involved with social services and those never known. The aim of this project was to examine mental ill-health amongst a cohort of all children aged 18 years and under based on care exposure including Looked After Children (LAC) placed in foster/kinship/residential care, Children in Need (CIN) known to social services but not removed from home and those never known.

Methods This data linkage study linked population-wide primary care registration data to children's social care records, prescribed medication data and hospital records. Data were used to determine the period prevalence of mental ill-health in 2015 defined by receipt of psychotropic medication, psychiatric hospital admission and/or presentation to Emergency Department for self-harm. Logistic regression quantified the likelihood of each mental health outcome with adjustment for factors associated with mental ill-health and self-harm. 